\title{
BINDING POLYNOMIAL OF A GRAPH
}

\section{KIRAN S}

Department of Mathematics, Bangalore University, Central College Campus, Bengaluru, India

\section{ABSTRACT}

We introduce here a new concept called the binding polynomial of a graph $G$ to cater the needs of addressing the local and global binding number of a graph. The binding polynomial of $G$, denoted by $b^{p}(G)$, is defined as $b^{p}(G)=$ $\sum_{i=1}^{n} \operatorname{bind}_{v_{i}}(G) x^{\operatorname{deg}\left(v_{i}\right)}$. The binding polynomials of some standard graphs have been established here.

KEYWORDS: Binding Number, Local Binding Number, Binding Degree of a Vertex

Received: Oct 16, 2020; Accepted: Nov 06 2020; Published: Nov 28, 2020; Paper Id.: IJMCARDEC20206

\section{INTRODUCTION}

Throughout this paper, by a "graph" we mean a finite simple graph without loops as treated in F. Harary [3].

The binding number of a graph is a measure how well the edges are distributed over vertices. If a graph has lower binding number, then it conveys that, the edges are concentrated at some vertices, not uniformly over all. This nature of the binding number finds applications in network reliability. So the study of binding number has both theoretical as well as practical implications. Formally the binding number was defined by Woodall [9] in his seminal paper way back in 1947. It is considered to be one of the toughest graph parameters and hence find considerably less number of research papers in seven decades of study. Recently, it is extended for digraphs by Xu et al. [10]. For further details one can refer to [1], [6], [7], [8], [9].

In this paper we undertake a study on binding polynomial of a graph and related results, which we are introducing here. Till 2019 the study of binding number was considered as a single, major parameter for a graph. But the treatment got a new direction by Aslan [2], where it is considered and defined for each vertex of the graph under consideration and then the average was defined over all the vertices. This approach gives a local vulnerability test of the given graph or network. And this motivated us to define another new parameter namely the binding degree of a graph in [4], [5]. This works as a triple layered parameter combining the degree of a vertex and its local binding number, so that the duality of local connectedness and local vulnerability are addressed.

Going one more step ahead, we get the binding polynomial of a graph, which is the focal point of this article.

\section{BASICS}

Here we list some important definitions.

Definition: [9] The binding number of a graph $\mathrm{G}$ is defined as $d(G)=\min \left\{\frac{|N(X)|}{|X|}: X \subseteq V(G), X \neq\right.$ $\emptyset$ and $N(X) \neq V(G)\}$, where $N(X)=\{y: x y \in E(G) \forall x \in X\}$, is called the open neighbourhood set of X. 
Definition : [2] For $v \in V(G)$, the local binding number of $\mathrm{v}$ is $\operatorname{bind}_{v}(G)=\min _{v \in F_{v}(G)}\left\{\frac{|N(S)|}{|S|}\right\}$, where $F_{v}=\{S \subseteq V(G): v \in$ $S, S \neq \emptyset, N(S) \neq V(G)\}$

Clearly, $\operatorname{bind}(G)=\min _{v \in V(G)}\left\{\operatorname{bind}_{v}(G)\right\}$. A local binding set of $\mathrm{v}$ in $\mathrm{G}$ is $S \in f_{v}(G)$, such that $\operatorname{bind}_{v}(G)=\frac{|N(S)|}{|S|}$.

Definition : $\quad$ The average binding number of $\mathrm{G}$ is defined as $\operatorname{bind}_{a v}(G)=\frac{1}{n} \sum_{v \in V(G)} \operatorname{bind}_{v}(G)$. where $\mathrm{n}$ is the number of vertices in graph $\mathrm{G}$.

Definition :[4] The binding degree of $\mathrm{G}$, denoted by $b^{d}(G)$, is defined as $b^{d}(G)=\sum_{i=1}^{n} \operatorname{deg}\left(v_{i}\right) \operatorname{bind}_{v_{i}}(G)$.

\section{RESULTS}

Motivated by all the above treatments of binding number we define here the binding polynomial of a graph. This is in line with any parameter related polynomial like domination polynomial. We formally define it here and prove some related results.

Definition : The binding polynomial of a graph $\mathrm{G}$, denoted by $\mathrm{b}^{\mathrm{p}}(\mathrm{G})$, is defined as $b^{p}(G)=\sum_{i=1}^{n} \operatorname{bind}_{v_{i}}(G) x^{\operatorname{deg}\left(v_{i}\right)}$. Illustration:

In $G$, we have $|V(G)|=4$ and $|E(G)|=4$.

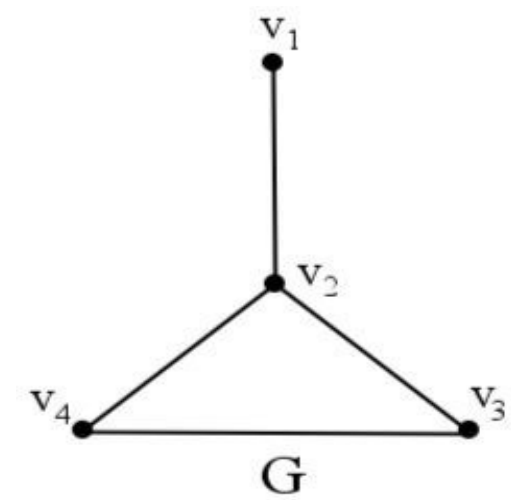

Note that, $\operatorname{bind}_{v_{1}}(G)=1, \operatorname{deg}\left(v_{1}\right)=1, \quad \operatorname{bind}_{v_{2}}(G)=3, \operatorname{deg}\left(v_{2}\right)=3, \quad \operatorname{bind}_{v_{3}}(G)=1, \operatorname{deg}\left(v_{3}\right)=2$ and $\operatorname{bind}_{v_{4}}(G)=1, \operatorname{deg}\left(v_{4}\right)=2$ It follows that, $b^{p}(G)=x+2 x^{2}+3 x^{3}$.

Proposition 3.1 : The binding polynomial of cycles, paths, complete graphs, complete bipartite graphs, wheels is given as follows:

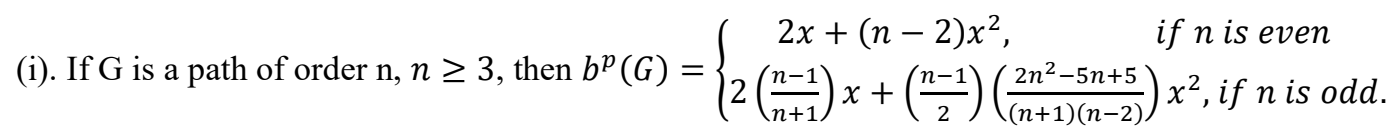

(ii). If $\mathrm{G}$ is a cycle of order $\mathrm{n}, n \geq 3$, then $b^{p}(G)=\left\{\begin{array}{c}n x^{2}, \quad \text { if } n \text { is even } \\ n\left(\frac{n-1}{n-2}\right) x^{2}, \text { if } n \text { is odd. }\end{array}\right.$

(iii). If $\mathrm{G}$ is a complete graph of order $\mathrm{n}, n \geq 3$, then $b^{p}(G)=n(n-1) x^{n-1}$.

(iv). If $\mathrm{G}$ is a complete bipartite graph of order $\mathrm{m}$ and $\mathrm{n}, m, n \geq 2$, then $b^{p}(G)=m x^{m}+n x^{n}$. 
(v). For $n \geq 4$, the binding polynomial of a wheel is, $b^{p}(G)=\left\{\begin{array}{l}\frac{(n-1)^{2}}{n-3}+(n-1) x^{n-1}, \quad \text { if } n \text { is even } \\ (n+1) x^{3}+(n-1) x^{n-1}, \text { if } n \text { is odd. }\end{array}\right.$

Proof: (i) Let $P_{n}$ be a path with $n \geq 3$ vertices. If the vertices of $P_{n}$ are labelled as $v_{1}, v_{2}, \ldots, v_{n}$ then we know that $\operatorname{deg}\left(\mathrm{v}_{1}\right)=\operatorname{deg}\left(\mathrm{v}_{\mathrm{n}}\right)=1 \$$ and $\operatorname{deg}\left(\mathrm{v}_{2}\right)=\ldots=\operatorname{deg}\left(\mathrm{v}_{\mathrm{n}-1}\right)=2$. Here we consider two cases.

Case (a): $n$ be even.

From [9] we know that bind $\left(\mathrm{P}_{\mathrm{n}}\right)=1$, whenever $\mathrm{n}$ is even. For $v_{i} \in V\left(P_{n}\right)$ the local binding number of $\mathrm{v}_{\mathrm{i}}$ with $1 \leq$ $i \leq n$ is $\operatorname{bind}_{v_{i}}\left(P_{n}\right)=1$. Therefore $b^{p}(G)=2 x+(n-2) x^{2}$.

Case (b): $\mathrm{n}$ be odd.

For $v_{i} \in V\left(P_{n}\right)$, the local binding number of $\left\{\mathrm{v}_{1}, \mathrm{v}_{2}, \ldots, \mathrm{v}_{\mathrm{n}}\right\}$ is $\operatorname{bind}_{v_{i}}\left(P_{n}\right) \frac{n-1}{n+1}$ and the local binding number of $\left\{\mathrm{v}_{2}, \quad \mathrm{~V}_{4}, \ldots, \quad \mathrm{V}_{\mathrm{n}-1}\right\} \quad$ is $\quad \operatorname{bind}_{v_{i}}\left(P_{n}\right) \frac{n-1}{n-2} . \quad$ Therefore $\quad b^{p}(G)=2 \frac{n-1}{n+1} x+\left(\frac{n-3}{2}\right)\left(\frac{n-1}{n+1}\right) x^{2}+\left(\frac{n-1}{2}\right)\left(\frac{n-1}{n-2}\right) x^{2}=2\left(\frac{n-1}{n+1}\right) x+$ $\left(\frac{n-1}{2}\right)\left(\frac{2 n^{2}-5 n+5}{(n+1)(n-2)}\right) x^{2}$. Hence the result.

(ii)

Let $C_{n}$ be a cycle with $n \geq 3$ vertices. We know that $C_{n}$ is a self-centred, regular graph of regularity 2 . Here also we have two cases.

Case (a) : $n$ be even.

Form [9] we know that bind $\left(\mathrm{C}_{\mathrm{n}}\right)=1$ if $\mathrm{n}$ is even. Therefore $b^{p}(G)=n x^{2}$

Case (b): $n$ be odd.

from [9] we know that $\operatorname{bind}\left(C_{n}\right)=\frac{n-1}{n-2}$ for $\mathrm{n}$ odd. Therefore $b^{p}(G)=n\left(\frac{n-1}{n-2}\right) x^{2}$. Hence the result.

(iii)

Since a complete graph $\mathrm{K}_{\mathrm{n}}$, for $n \geq 3$ is a regular graph of regularity $\mathrm{n}-1$ and all vertices have local binding number $\mathrm{n}-1$, we get $b^{p}(G)=n(n-1) x^{n-1}$.

Let $\mathrm{K}_{\mathrm{m}, \mathrm{n}}$ be a complete bipartite graph. Let vertices be labelled as $\$ \mathrm{v}_{1}, \mathrm{v}_{2}, \ldots, \mathrm{v}_{\mathrm{m}}, \mathrm{u}_{1}, \mathrm{u}_{2}, \ldots, \mathrm{u}_{\mathrm{n}}$. For $v_{i} \in V\left(K_{m, n}\right)$, the local binding number of $\mathrm{v}_{\mathrm{i}}$ for $1 \leq i \leq m$, is $\operatorname{bind}_{v_{i}}\left(K_{m, n}\right)=\frac{n}{m}$ and the local binding number of $\mathrm{u}_{\mathrm{j}}$ for $1 \leq j \leq n$, is $\operatorname{bind}_{v_{j}}\left(K_{m, n}\right)=\frac{m}{n}$. Therefore $b^{p}(G)=n \frac{m}{n} x^{m}+m \frac{n}{m} x^{n}=m x^{m}+n x^{n}$.

(v)

Let $\mathrm{W}_{\mathrm{n}}$ be a wheel with $n \geq 4$. We know that $\mathrm{W}_{\mathrm{n}}=\mathrm{C}_{\mathrm{n}-1}+\mathrm{K}_{1}$. If $\mathrm{W}_{\mathrm{n}}$ has $\left\{\mathrm{v}_{1}, \mathrm{v}_{2}, \ldots, \mathrm{V}_{\mathrm{n}}\right\}$ vertices, we know that $\operatorname{deg}\left(\mathrm{v}_{\mathrm{n}}\right)=\mathrm{n}-1$ and $\operatorname{deg}\left(\mathrm{v}_{1}\right)=\operatorname{deg}\left(\mathrm{v}_{2}\right)=\ldots=\operatorname{deg}\left(\mathrm{v}_{\mathrm{n}-1}\right)=3$. Here we have two cases.

Case (a):n be even.

For $v_{i} \in V\left(W_{n}\right)$, from [2], the local binding number of $\mathrm{v}_{\mathrm{i}}$ for $1 \leq i \leq n-1$ is $\operatorname{bind}_{v_{i}}\left(W_{n}\right)=\frac{n-1}{n-3}$ and the local 
binding number of $\mathrm{v}_{\mathrm{n}}$ is $\operatorname{bind}_{v_{n}}\left(W_{n}\right)=n-1$. Therefore $b^{p}(G)=(n-1) \frac{n-1}{n-3} x^{3}+(n-1) x^{n-1}=\frac{(n-1)^{2}}{n-3} x^{3}+(n-$ 1) $x^{n-1}$.

ICase (b): $n$ be odd.

For $v_{i} \in V\left(W_{n}\right)$, from [2], the local binding number of $\mathrm{v}_{\mathrm{i}}$ for $1 \leq i \leq n-1$ is $\operatorname{bind}_{v_{i}}\left(W_{n}\right)=\frac{n+1}{n-1}$ and the local binding number of $\mathrm{v}_{\mathrm{n}}$ is $\operatorname{bind}_{v_{n}}\left(W_{n}\right)=n-1$. Therefore $b^{p}(G)=(n-1) \frac{n+1}{n-1} x^{3}+(n-1) x^{n-1}=(n+1) x^{3}+(n-$ 1) $x^{n-1}$.

Hence the result.

Proposition 3.2 : The binding polynomial of a fan graph and a double star is given as follows:

(i) For a fan graph $F_{n}$ with $n \geq 4$ vertices,

$b^{p}\left(F_{n}\right)=\left\{\begin{array}{c}2 x^{2}+\frac{n^{2}-5 n+7}{n-3} x^{3}+(n-1) x^{(n-1)}, \quad \text { if } n \text { is even } \\ 2\left(\frac{n-1}{n-2}\right) x^{2}+\frac{n^{2}-4 n+3}{n-2} x^{3}+(n-1) x^{n-1}, \text { if } n \text { is odd } .\end{array}\right.$

(ii)] For a double star graph $\mathrm{S}_{\mathrm{m}, \mathrm{n}}$ with $\mathrm{m}, \mathrm{n} \geq 2$ vertices, $b^{p}\left(S_{m, n}\right)=\left\{\begin{array}{c}2 x+2 \frac{m+1}{2 m+1} x^{m}, \quad \text { if } m=n, \\ \frac{3 m+n-4}{m+n-2} x+\frac{m+1}{m+n-1} x^{m}+\frac{n+1}{m+n-1} x^{n}, \text { if } m<n, \\ \frac{m+3 n-4}{m+n-2} x+\frac{m+1}{m+n-1} x^{m}+\frac{n-1}{m+n-1} x^{n}, \text { if } n<m .\end{array}\right.$

Proof: (i)

Let $\mathrm{F}_{\mathrm{n}}$ be a fan graph with $\mathrm{n} \geq 4$, labelled $\mathrm{v}_{1}, \mathrm{v}_{2}, \ldots, \mathrm{v}_{\mathrm{n}}$ vertices. We know that $\operatorname{deg}\left(\mathrm{v}_{\mathrm{n}}\right)=\mathrm{n}-1, \operatorname{deg}\left(\mathrm{v}_{1}\right)=\operatorname{deg}\left(\mathrm{v}_{\mathrm{n}-1}\right)=2$ and $\operatorname{deg}\left(\mathrm{v}_{2}\right)=\operatorname{deg}\left(\mathrm{v}_{3}\right)=\ldots=\operatorname{deg}\left(\mathrm{v}_{\mathrm{n}-2}\right)=3$. Here we have two cases.

Case (a):n be even.

For $v_{i} \in V\left(F_{n}\right)$, $\mathrm{i}=2,4, \ldots, \mathrm{n}-1$, the local binding number is $\operatorname{bind}_{v_{i}}\left(F_{n}\right)=1$, the local binding number of $\mathrm{v}_{3}, \mathrm{v}_{5}, \ldots$, $\mathrm{v}_{\mathrm{n}-2}$ is $\operatorname{bind}_{v_{i}}\left(F_{n}\right)=\frac{n-1}{n-3}$ and the local binding number of $\mathrm{v}_{\mathrm{n}}$ is $\operatorname{bind}_{v_{i}}\left(F_{n}\right)=\mathrm{n}-1$. Therefore $b^{p}\left(F_{n}\right)=2 x^{2}+\left(\frac{n-4}{2}\right) x^{3}+$ $\left(\frac{n-2}{2}\right)\left(\frac{n-1}{n-3}\right) x^{3}+(n-1) x^{n-1}=2 x^{2}+\frac{n^{2}-5 n+7}{n-3} x^{3}+(n-1) x^{n-1}$.

Case (b): $\mathrm{n}$ be odd.

For $v_{i} \in V\left(F_{n}\right)$, the local binding number of $\mathrm{v}_{\mathrm{i}}$ with $1 \leq \mathrm{i} \leq \mathrm{n}-1$ is $\operatorname{bind}_{v_{i}}\left(F_{n}\right)=\frac{n-1}{n-2}$ and the local binding number of $\mathrm{V}_{\mathrm{n}}$ is $\operatorname{bind}_{v_{n}}\left(F_{n}\right)=\mathrm{n}-1$. Therefore $b^{p}\left(F_{n}\right)=2\left(\frac{n-1}{n-2}\right) x^{2}+\frac{n^{2}-4 n+3}{n-2} x^{3} \quad+(n-1) x^{n-1} \quad$. Hence the result.

(ii)

Let $\mathrm{S}_{\mathrm{m}, \mathrm{n}}$ be a double star with $\mathrm{m}, \mathrm{n} \geq 2$, and hence $\mathrm{S}_{\mathrm{m}, \mathrm{n}}=\overline{k_{m-1}}+\mathrm{K}_{1}+\mathrm{K}_{1}+\overline{k_{n-1}}$. If $\mathrm{S}_{\mathrm{m}, \mathrm{n}}$ has $\mathrm{v}_{1}, \mathrm{v}_{2}, \ldots, \mathrm{v}_{\mathrm{m}}, \mathrm{u}_{1}, \mathrm{u}_{2}, \ldots$, $\mathrm{u}_{\mathrm{n}}$ vertices with $\operatorname{deg}\left(\mathrm{v}_{1}\right)=\operatorname{deg}\left(\mathrm{v}_{2}\right)=\ldots .=\operatorname{deg}\left(\mathrm{v}_{\{\mathrm{m}-1\}}\right\}=\operatorname{deg}\left(\mathrm{u}_{1}\right)=\operatorname{deg}\left(\mathrm{u}_{2}\right)=\ldots=\operatorname{deg}\left(\mathrm{u}_{\mathrm{n}-1}\right)=1, \operatorname{deg}\left(\mathrm{v}_{\mathrm{m}}\right)=\mathrm{m}$ and $\operatorname{deg}\left(\mathrm{u}_{\mathrm{n}}\right)=\mathrm{n}$, then we have three cases.

Case (a): $m=n$. 
For $\mathrm{v}_{\mathrm{i}} \in \mathrm{S}_{\mathrm{m}, \mathrm{n}}$, the local binding number of each vertex of $\mathrm{v}_{1}, \mathrm{v}_{2}, \ldots, \mathrm{v}_{\{\mathrm{m}-1\}}$ is $\operatorname{bind}_{v_{i}}\left(S_{m, n}\right)=\frac{1}{m-1}$ from [2], and that of each of $\mathrm{u}_{1}, \mathrm{u}_{2}, \ldots, \mathrm{u}_{\{\mathrm{m}-1\}}$ as $\operatorname{bind}_{u_{i}}\left(S_{m, n}\right)=\frac{1}{m-1}, \operatorname{bind}_{v_{m}}\left(S_{m, n}\right)=\frac{m-1}{2 m-1}$ for $\mathrm{v}_{\mathrm{m}}$ and is $\operatorname{bind}_{u_{m}}\left(S_{m, n}\right)=\frac{m+1}{2 m-1}$ for $\mathrm{u}_{\mathrm{m}}$. Therefore, the binding polynomial of the double star is,

$$
b^{p}\left(S_{m, m}\right)=2 x+2 \frac{m+1}{2 m+1} x^{m} .
$$

Case (b): $\mathrm{m}<\mathrm{n}$.

For $\mathrm{v}_{\mathrm{i}} \in \mathrm{S}_{\mathrm{m}, \mathrm{n}}$, the local binding number of each vertex $\mathrm{v}_{1}, \mathrm{v}_{2}, \ldots, \mathrm{v}_{\mathrm{m}-1}$ is $\operatorname{bind}_{v_{i}}\left(S_{m, n}\right)=\frac{2}{m+n-2}$ and that of $\mathrm{u}_{1}, \mathrm{u}_{2}, \ldots$, $\mathrm{u}_{\{\mathrm{n}-1\}} \operatorname{bind}_{u_{i}}\left(S_{m, n}\right)=\frac{1}{n-1}, \operatorname{bind}_{v_{m}}\left(S_{m, n}\right)=\frac{n+1}{m+n-1}$ for $\mathrm{v}_{\mathrm{m}}$ and $\operatorname{bind}_{u_{m}}\left(S_{m, n}\right)=\frac{n+1}{m+n-1}$ for $\mathrm{u}_{\mathrm{m}}$. Therefore

$$
\begin{gathered}
b^{p}\left(S_{m, n}\right)=(n-1) \\
\frac{1}{n-1} x+(m-1) \frac{2}{m+n-2} x+\frac{m+1}{m+n-1} x^{m}+\frac{n+1}{m+n-1} x^{n} \\
=\frac{3 m+n-4}{m+n-2} x+\frac{m+1}{m+n-1} x^{m}+\frac{n+1}{m+n-1} x^{n} .
\end{gathered}
$$

Case (c): $m>n$.

Similar to Case(b), we get,

$$
\begin{gathered}
b^{p}\left(S_{m, n}\right)=(m-1) \frac{1}{m-1} x+(n-1) \frac{2}{m+n-2} x+\frac{m+1}{m+n-1} x^{m}+\frac{n+1}{m+n-1} x^{n} \\
=\frac{m+3 n-4}{m+n-2} x+\frac{m+1}{m+n-1} x^{m}+\frac{n+1}{m+n-1} x^{n} .
\end{gathered}
$$

Hence the result.

\section{CONCLUSIONS}

In this paper we have introduced the binding polynomial of a graph. We have determined the polynomial for some familiar class of graphs. Determining for many other classes, find the roots of these polynomials, their multiplicities, their relation to the local, average binding number, etc. are being explored further.

\section{REFERENCES}

1. 1. I. Anderson, "Binding number of a graph, A survey in graph Theory",Advances in Graph Theory, Vishwa International Publications, 1-10, Gulbarga(India), 1991.

2. 2. E. Aslan, "The Average Binding Number of Graphs", Science Asia, 45, 85-91, 2019.

3. U. V. S. Seshavatharam \& S. Lakshminarayana, "Logic Behind the Squared Avogadro Number and SUSY «, International Journal of Applied and Natural Sciences(IJANS), Vol. 2, No 2, pp. 23-40

4. Vivek N. Waghmare \& Ravindra C. Thool, «Encrypted Signature Scheme for Secure \& Selective Dissemination of Tree Structured Data (XML) «, International Journal of Computer Science and Engineering (IJCSE), Vol. 3, No. 3, pp. 31-40

5. 3. F. Harary, Graph Theory, Addison Wesley/ Narosa Publishing House Reprint 1988, 10th reprint; 2001.

6. 4. Medha Itagi Huilgol, S. Kiran, “Changes in binding number and binding degree under edge operations ", (Communicated).

7. 5. Medha Itagi Huilgol, S. Kiran, "Mean closed binding number and binding degree of a graph", (Communicated).

8. 6. V. G. Kane, Doctoral Thesis, “'On binding number of a graph", Indian Institute of Technology, Kanpur, India, 1976. 
9. 7. H. B. Walikar, B. B. Mulla, "On graphs with binding number one", International Journal of Pure and Applied Mathematics, 98, 413-418, 2015.

10. 8. H. B. Walikar, B. B. Mulla, "Power of a graph and binding number", International Journal of Pure and Applied Mathematics, 101, 505-511, 2015.

11. 9. D. R. Woodall, "The binding number of a graph and its Anderson number", J. Combinatorial Theory Ser. B, 15, 225-255, 1973.

12. Anar Bakieva, Mukhamedzhan Akimov, Galiya Abdilova, Nadir Ibragimov \& Gulvira Bekeshova, "Developing New type of Disk Plate for Meat Chopper and its Effect to Water-Binding Capacity and Yield Stress of Minced Meat ", International Journal of Mechanical and Production Engineering Research and Development (IJMPERD), Vol. 9, No. 6, pp. 377-390

13. Abeer Abduljabbar Abdulabbas \& Y. K. Bind, "Estimation of Shear Strength Parameters of Soils Using ANN Technique ", International Journal of Civil, Structural, Environmental and Infrastructure Engineering Research and Development (IJCSEIERD), Vol. 4, No 3, pp. 1-10

14. 10. G. Xu, X. Li, S. Zhang, 'The binding number of a digraph", CJCDGCGT 2005, LNCS 4381, 221-227, 2007. 